\title{
O Programa de Pré-Iniciação Científica da USP
}

Resumo: O Programa de Pré-Iniciação Científica da USP, constituído de bolsas de pesquisa oferecidas aos alunos da rede pública, é uma iniciativa inovadora que busca aproximar o Ensino Médio da Universidade, promovendo o desenvolvimento pessoal e profissional dos alunos, bem como a promoção de atividade educativa e científica na Universidade. Pela importância social e pedagógica desse Programa, convidamos seu coordenador, o Prof. Dr. Pedro Primo Bombonato, para ser o nosso entrevistado deste número.

Palavras-chave: iniciação científica, pesquisa, universidade, ensino médio, educação.
Abstract: USP's Science Training Program for Secondary Education, constituted by research scholarships for public schools students, is an innovational initiative oriented to bring together High School and the University, promoting students personal and professional development, as well educative and scientific activities in the University. Because of this program's social and pedagogic importance, its coordinator, Prof. Dr. Pedro Bombonato, was invited to be our interviewee.

Keywords: Science training, research, university, seconday school, high school, education.

No mês de outubro de 2008 foi lançado o Programa de Pré-Iniciação Científica da USP, uma iniciativa da Pró-Reitoria de Pesquisa, visando estabelecer uma relação pedagógica e de pesquisa entre alunos da rede pública do Estado de São Paulo e os grupos de pesquisa existentes na Universidade de São Paulo. Tendo como parceiros a Secretaria de Educação do Estado de São Paulo e o Banco Santander, o Programa é constituído de bolsas de pesquisa oferecidas aos alunos da rede pública que mais se destacam, para o desenvolvimento de atividades científicas e artísticas na Universidade. Trata-se de uma ação inovadora que busca aproximar o Ensino Médio da Universidade, promovendo o desenvolvimento pessoal e profissional dos alunos, bem como a promoção de atividade educativa e científica na Universidade, beneficiando a escola pública e a própria instituição que tem nesse Programa a oportunidade de intervir e colaborar com a melhoria da sociedade. Pela importância social e pedagógica desse Programa, convidamos seu coordenador, o Prof. Dr. Pedro Bombonato, para ser o nosso entrevistado deste número. Quando nossos leitores estiverem tomando contato com este material, mais de 400 alunos da rede pública do Estado de São Paulo já estarão há meses trabalhando junto aos laboratórios de pesquisa científica e artística da USP, numa aproximação inédita que beneficiará todos os envolvidos. Esperando que esse exemplo sirva de modelo para outras iniciativas semelhantes, desejamos informar nossos leitores a respeito de seus princípios e critérios.

Por Maria Cristina Castilho Costa

Recebido: 03.10 .2008

Aprovado: 06.10 .2008 
comunicação \& educação • Ano XIV • Número 1 • jan/abr 2009

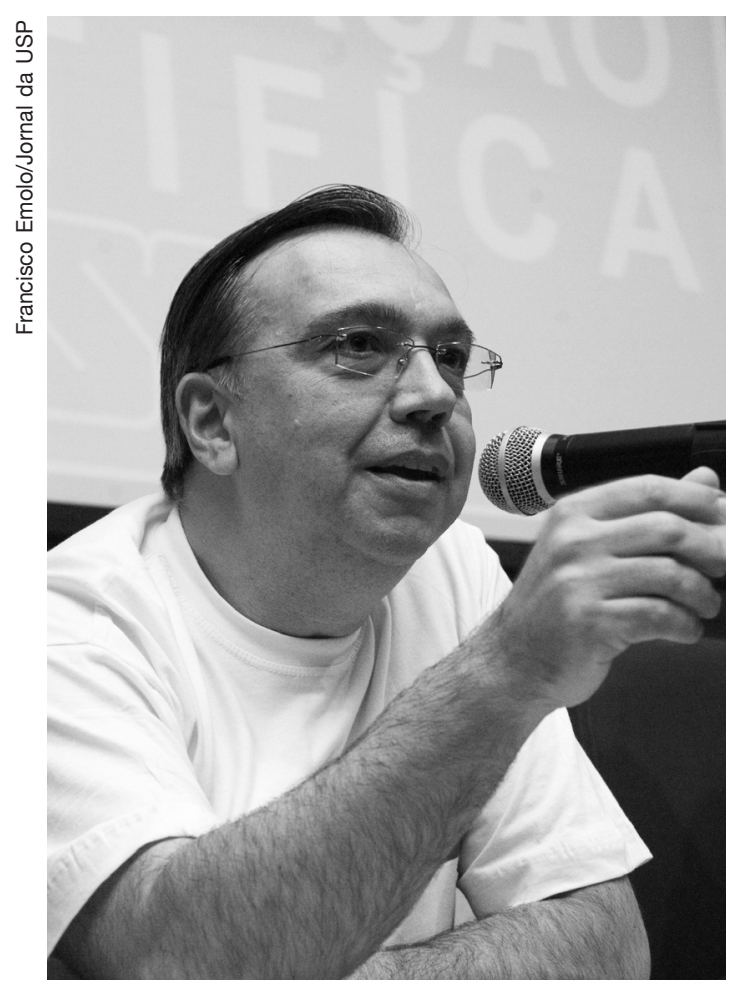

Pedro Primo Bombonato

C\&E: Professor, quais são os principais objetivos do Programa de Pré-Iniciação Científica que o senhor coordena?

Bombonato: Contribui, de alguma maneira, para a melhoria do ensino básico no País e, desse modo, pode ajudar na amenização das desigualdades sociais com as quais nos deparamos. Sabemos que ainda é pouco, mas acreditamos que os alunos envolvidos no programa possam ser contagiados pela curiosidade e que essa experiência junto à Universidade ajude a desenvolver sua motivação para o aprendizado.

C\&E: Qual o papel da Secretaria de Educação do Estado de São Paulo nessa parceria?

Bombonato: Cabe à Secretaria da Educação do Estado de São Paulo indicar os alunos candidatos à bolsa e os professores que supervisionarão os grupos de suas escolas. Para se candidatarem à bolsa é preciso ter bom desempenho escolar, não estar integrado ao mercado de trabalho e dispor de 8 horas semanais para trabalho de pesquisa.

C\&E: Nesse programa, qual o papel da USP?

Bombonato: A Universidade seleciona os projetos de laboratórios e grupos de pesquisa científica, tecnológica e artística. Compromete-se também a fazer a avaliação periódica do programa, acompanhando o desempenho dos bolsistas junto aos laboratórios. Com base nessa seleção, a USP divulga o número de vagas existentes para os bolsistas, indicando as áreas em que incluem esses projetos, bem como as unidades em que os mesmos se desenvolvem. Também é papel da Universidade cuidar da capacitação dos professores-supervisores através de seminários, encontros e outras atividades como cursos de atualização de 48 horas. Esse trabalho se constitui em uma formação continuada desses supervisores. É a Universidade que emite certificados de participação no Programa de Pré-Iniciação Científica para todos os envolvidos - alunos, professores da rede pública e professores-pesquisadores responsáveis pelos laboratórios. 
C\&E: Quais são os demais parceiros?

Bombonato: Temos ainda como parceiros o Banco Santander S/A, responsável pelo pagamento das bolsas aos alunos, e a FUSP, que administra os pagamentos aos bolsistas e professores-supervisores.

C\&E: $O$ que a USP espera desses bolsistas?

Bombonato: Essa proposta tem como principal objetivo aproximar a Universidade da rede pública de ensino. Durante muito tempo fomos criticados por não dar atenção a outros níveis de ensino que não o produzido pela Universidade. E esse é um programa que estende o braço da Universidade para a rede pública e reconstrói uma teia de relações entre diferentes níveis de ensino. Nosso principal objetivo é ensinar esse aluno a pensar. Não será oferecido a ele nenhum conjunto de conhecimentos ou informações, ou programática preestabelecida. O que desejamos é que, utilizando a pesquisa como ferramenta, cada aluno construa para si um modelo de solução de problemas. Ele deve aprender a pensar problemas e solucioná-los.

C\&E: Qual é a abrangência desse programa?

Bombonato: Ele abrange os diversos campi da Universidade pelos quais serão distribuídos os bolsistas que desempenharão atividades em laboratórios de pesquisa. Procuramos respeitar a proximidade do aluno, favorecendo sua locomoção até a Universidade. Esperamos que essa vivência seja motivadora e venha complementar o seu desenvolvimento humano e individual.

C\&E: Esse periodo de atividades junto aos laboratórios de pesquisa contará créditos nos exames vestibulares da USP?

Bombonato: Não, e não é este o nosso objetivo. Melhoria do rendimento escolar, maior índice de aprovados no vestibular provenientes da rede pública, melhor capacitação para o mercado de trabalho não são metas desse programa. Serão e poderão vir a ser consequências. O que aspiramos é que esse aluno venha a aprender a pensar e a resolver problemas. É claro que, à medida que ele ganha essa aptidão e essa habilidade, terá maior rendimento escolar, terá a grife da Universidade para uma melhor inserção no mercado de trabalho e vai se sentir mais próximo da Universidade; portanto, terá interesse em fazer parte dela. Há um processo de dessacralização da Universidade por parte do aluno que o aproximará dela, mas todas essas são consequências do programa e não nossas propostas. Não é isso que temos como metas de avaliação futura.

C\&E: Esse programa enfrentou resistências dentro da Universidade?

Bombonato: O programa em si não, mas alguns parceiros que procuramos apresentaram resistências. A ideia do programa sempre foi muito bem recebida e aceita, mas dentro da Universidade há os que pensam que qualquer iniciativa deva ser proposta, patrocinada e mantida por ela. Há os que acham 
comunicação \& educação • Ano XIV • Número 1 • jan/abr 2009

que as ações conjuntas da Universidade com empresas privadas possam contribuir efetivamente para a construção de diferentes modelos. Então, aqueles que imaginam que a Universidade tem de bancar todo o custo do projeto, fizeram resistência quanto à forma de consecução do programa, e não ao programa em si mesmo.

C\&E: Dentro da USP foi fácil abrir espaço para esse pequeno número de alunos? Bombonato: Num primeiro instante, não. Tudo aquilo que é novo e diferente encontra um pouco de oposição. Então, o professor demonstra preocupação ao abrir a porta do seu laboratório; quer saber quem é esse aluno que vai entrar, o que ele vai fazer no "meu laboratório". E essa incerteza causa certa reação. Passado esse momento, começa um segundo nível de relação, que é a construção da credibilidade. Quando o programa alcançá-la, essas resistências iniciais serão facilmente resolvidas. Foi assim com outros programas. O próprio Programa de Iniciação Científica, quando foi constituído, começou com uma centena de alunos. Hoje a Universidade tem sete mil bolsistas. O programa ao longo do tempo tende a ganhar credibilidade pelos resultados que apresenta e pelas características de formulação que venha a ter. No início, as resistências foram relativas ao medo do novo, mas a credibilidade crescente acabará com elas. Hoje temos uma demanda muito maior do que o número de laboratórios disponíveis. Nossa meta é que cada laboratório existente na USP venha a ter pelo menos um bolsista de Pré-Iniciação Científica. Quando isso acontecer, contaremos com cerca de 1.900 alunos participantes. Esse é nosso objetivo.

C\&E: Esse programa foi inspirado em outro programa existente no Brasil ou no exterior?

Bombonato: Existem vários programas que fazem essa ponte entre a universidade e o ensino fundamental e ensino médio, mas esse, em especial, tem características que o diferenciam dos demais, como o do México, de Israel, da Alemanha e mesmo do programa do CNPq, existente no Brasil. O Programa do México oferece um pacote predeterminado para o aluno - ele sabe o que vai fazer e todos farão a mesma coisa, em tempos diferentes, mas todos cumprirão as mesmas etapas do processo. O nosso não. Nele, cada aluno passará por uma experiência diferente e todos construirão para si próprios um modelo de formação do pensamento científico. E é esse mosaico de experiências que vai impactar a escola de origem dos alunos. Nosso programa se diferencia do programa do CNPq porque o aluno não está disperso, está reunido em grupos, embora em laboratórios diferentes, com experiências diversas, mas constituindo um grupo supervisionado por um professor da escola que retorna a ela na forma de grupo. A expectativa é que isso quebre o paradigma de uma agulha perdida num palheiro, pois sozinho pode ser que ele não consiga impactar a escola nem possa se tornar de fato um agente modificador. Por estar em grupo e ser 
supervisionado por um professor, esse programa diferencia-se daquele do MEC, da Fiocruz, do CNPq, outros da melhor qualidade, mas com um modus operandi diferente do nosso.

C\&E: Esses programas existentes no Brasil têm dado bons resultados?

Bombonato: Sim, excelentes, muito promissores. Nos dias 30 e 31 de outubro de 2008, a Fiocruz estará realizando o segundo seminário de avaliação do programa deles e os dados preliminares são de excelente qualidade.

C\&E: O senhor vê a possibilidade de outras universidades virem a desenvolver programas de Pré-Iniciação Científica?

Bombonato: Creio que um dos potenciais da USP é o de ser o dínamo de várias ações. Sempre que ela age, as coisas começam a tomar dimensões não só nacionais como internacionais. Nós esperamos que o exemplo da Universidade seja seguido por outras instituições. Até já fui contatado por uma grande universidade particular que deseja implantar programa semelhante.

C\&E: O que o senhor espera que esse aluno nos ensine?

Bombonato: Muitas coisas. A primeira é a necessidade de a universidade olhar para outros níveis de ensino e não só o universitário, aquele que representa mais diretamente a sua vocação. Esses alunos vão nos ensinar que a escada social pode ser construída pela universidade. Trarão para dentro dela uma realidade para a qual, às vezes, muitos dos nossos alunos e professores, mesmo conhecendo, não estão atentos. Vão trazer uma relação de pessoalidade diferente daquela do aluno da universidade. Nosso aluno, quando entra na universidade, já vem motivado, vem com uma carreira pré-definida para a qual pretende se dedicar. Nosso aluno bolsista, não. A motivação dele vai ser a utilização da ferramenta da curiosidade, da pesquisa. Olhar esse aluno vai nos ajudar a entender melhor como motivar os nossos alunos mais efetivamente, com mais qualidade. O processo vocacional passa pela motivação. Vamos aprender a criar novos níveis de motivação que possam ser aproveitados. O que se espera é que o professor e o pesquisador da USP possam aproveitar a experiência com esses alunos.

C\&E: A mídia tem aberto espaço para repercutir esse programa?

Bombonato: Tem. Claro que, como sempre, assuntos relacionados com a educação não ganham a primeira página. Talvez os nossos órgãos de imprensa devessem se pautar por outros critérios que faltam nas primeiras páginas dos jornais, hoje dedicados às tragédias, ao desconforto, às crises. A educação fica sempre relegada às páginas menos importantes. Mas houve espaço, sim, tivemos acompanhamento de vários órgãos - jornais, revistas, programas de televisão, sites, sempre dentro daquele espaço dedicado à educação. 
C\&E: Como esses alunos serão recebidos?

Bombonato: Para recebê-los realizamos uma cerimônia presidida pela PróReitora Mayana Zatz, da qual participaram nossos parceiros. Falamos para bolsistas e professores supervisores da importância que damos a essa iniciativa da Universidade. Demos as boas-vindas aos bolsistas e mostramos que era com grande emoção que víamos realizados os nossos sonhos. Depois dessa cerimônia, cada unidade promove sua própria recepção, de modo a receber os alunos e aclimatá-los ao campus onde vão trabalhar. Temos realizado também reuniões com os professores-coordenadores de pesquisa a respeito de como tratar com esses alunos que são, para todos os efeitos, bolsistas da USP, com direito ao uso das instalações e bibliotecas. Esperamos estar, de alguma forma, estreitando laços, aproximando professores e alunos, numa experiência nova de integração da Universidade à sociedade civil. 